\title{
ERRATUM
}

\section{Erratum to: Industrial water treatment and industrial marine outfalls: Achieving the right balance}

\author{
Adrian W. K. Law (凶) $)^{1,2}$, Chunyan Tang ${ }^{1,2}$ \\ 1 Environmental Process Modelling Centre, Nanyang Environment and Water Research Institute, Nanyang Technological University, Singapore \\ 637141, Singapore \\ 2 School of Civil and Environmental Engineering, Nanyang Technological University, Singapore 639798, Singapore
}

(C) Higher Education Press and Springer-Verlag Berlin Heidelberg 2017

Erratum to: Frontiers of Chemical Science and Engineering, 2016, 10(4), 472-479.

DOI 10.1007/s11705-016-1592-0

The authors regret that there was an error in the paper (Page 475, Section 3) describing the outfall database. It is not hosted by the first author at NTU. The correct statement should be: outfall database (http://www.outfalls.net.ms/, initiated by Prof. Gerhard Jirka at Karlsruhe Institute of Technology and maintained by Prof. Tobias Bleninger before 2014). The authors would like to apologize for any inconvenience caused.

The online version of the original article can be found at http://ink.springer.com/article/10.1007/s11705-016-1592-0

E-mail: cwklaw@ntu.edu.sg 